\title{
COTIDIANO, IMPRENSA E POLÍTICA: \\ A CONSTRUÇÃO SIMBÓLICA DA CIDADE DE GOIÂNIA POR INTERMÉDIO DO JORNAL O POPULAR
}

\author{
George Leonardo Seabra Coelho* \\ *Universidade Federal do Tocantins, Programa de Pós-graduação em História das Populações Amazônicas \\ (PPGHispam), Porto Nacional, TO, Brasil
}

\begin{abstract}
Resumo
Este artigo discute a relação entre a imprensa e o espaço urbano na construção simbólica da cidade de Goiânia. O estudo se detém no período entre a criação do jornal o Popular até a inauguração oficial da cidade, em 1942. Para tanto, faz-se um breve retrospecto da ascensão política de Pedro Ludovico Teixeira, contemplando o projeto de transferência da capital de Goiás e a criação de o Popular. Destaca-se como esse diário inseriu o leitor nas opções de lazer no novo espaço urbano e na promoção do Batismo Cultural. Por último, apresenta-se como o diário noticiou a "campanha pró-bandeirante" como estratégia de aproximação simbólica entre a nova capital e o projeto estadonovista. Como se verá, esse jornal cumpriu dois papéis no cotidiano da cidade de Goiânia: i) como órgão noticioso das dinâmicas da nova cidade e ii) como órgão de propaganda política de alinhamento das elites locais em torno do projeto modernizador do Estado Novo.
\end{abstract}

Palavras-chave

Cidade; Notícia; Propaganda; Representação; Estado Novo. 


\title{
DAILY LIFE, PRESS AND POLITICS: THE SYMBOLIC CONSTRUCTION OF THE CITY OF GOIÂNIA THROUGH THE NEWSPAPER O POPULAR
}

\author{
George Leonardo Seabra Coelho* \\ *Universidade Federal do Tocantins, Programa de Pós-graduação em História das Populações Amazônicas \\ (PPGHispam), Porto Nacional, TO, Brazil
}

\begin{abstract}
This article will discuss the relationship between the press and the urban space in the symbolic construction of the city of Goiânia. This study will focus on the creation of the newspaper O Popular until the official inauguration of the city in 1942. For that, we will make a brief review of the political rise of Pedro Ludovico Teixeira, the project to transfer the capital of Goiás and the creation of the newspaper $O$ Popular. We will highlight how this diary introduced the reader to leisure options in this new urban space and the promotion of its cultural baptism. Finally, we will see how the daily reported the "campaign probandeirante" as a symbolic approximation strategy between the new capital and the new project. As we will see, this newspaper fulfilled two roles in the daily life of the city of Goiannia: i) as a news organ of the dynamics of this new city and ii) as a political propaganda organ for the alignment of local elites around the modernization project of the Estado Novo.

Keywords

City; News; Adverstising; Representation; New State.
\end{abstract}




\title{
COTIDIANO, IMPRENSA E POLÍTICA: A CONSTRUÇÃO SIMBÓLICA DA CIDADE DE GOIÂNIA POR INTERMÉDIO DO JORNAL O POPULAR
}

\author{
George Leonardo Seabra Coelho
}

Introdução

A abordagem histórica da imprensa escrita como produtora de "verdades" e porta-voz de uma realidade fragmentada surge acompanhada da percepção de como a cidade de Goiânia foi construída simbolicamente. No intuito de discutir essa relação, será analisado o processo que culminou com a divulgação, pelo jornal O Popular, do cotidiano da cidade de Goiânia nos primeiros anos após sua inauguração. Para tanto, investigam-se as estratégias elaboradas pelo corpo editorial do diário para noticiar essa nova realidade citadina. Para entender como isso ocorreu, o presente artigo aborda a construção da cidade de Goiânia com base no que se publicou no jornal $O$ Popular entre 1938 e 1942, o que possibilita vislumbrar as relações entre a imprensa, o espaço urbano e o poder político.

Na primeira seção, intitulada "Contexto goiano até a década de 1930 e a transferência da capital do estado de Goiás”, é feito um breve retrospecto da conjuntura política do estado de Goiás até a ascensão política de Pedro Ludovico Teixeira. Na segunda, nomeada "O jornal $O$ Popular e a construção de Goiânia: lazeres, edificações e o Batismo Cultural”, expõe-se como o referido diário contribuiu para a formação dessa paisagem urbana e de que maneira comunicou aos leitores as opções de lazer, as remodelações arquitetônicas e o Batismo Cultural da cidade. Por fim, na última seção, denominada "O discurso de colonização interna no estado de Goiás: a campanha pró-monumento aos bandeirantes”, discute-se como a edificação da estátua do bandeirante reforçou a ação do Estado interventor e, ao mesmo tempo, consolidou simbolicamente a aproximação entre essa cidade e o projeto estado-novista. 
Convidamos o leitor a acompanhar as formas como esse jornal divulgou os jogos de futebol, os bailes, os carnavais de rua, o Batismo Cultural da cidade e a inauguração do Monumento aos Bandeirantes.

1. Contexto goiano até a década de 1930 e a transferência da capital do estado de Goiás

Segundo Palacin (1994), Goiás - em meados da década de 1920 - não participava do processo de industrialização comum à região Centro-Sul. Além do distanciamento das correntes modernizadoras, a produção do estado estava basicamente voltada ao consumo interno, com pequeno comércio e baixíssima circulação monetária. Foi somente com a Crise de 1929 que Goiás ocupou um papel mais relevante, como fornecedor de produtos básicos para o mercado nacional e para a absorção da migração. De acordo com Chaul (1999), essa nova função da economia goiana se efetivou no interior da reorientação do sistema capitalista, em que a economia incentivou novas regiões a ocuparem outros papéis produtivos.

Diante da falta de expressão política e do aumento do poder econômico de grupos emergentes, alguns políticos passaram a criticar a oligarquia caiadista. ${ }^{1} \mathrm{Ma}$ chado (1990) lembra que esses opositores eram carentes de coesão política, porém a situação se transformou quando eles perceberam que as relações de poder em Goiás estavam entrelaçadas à conjuntura nacional. A partir daí, esses dissidentes iniciaram um movimento de contestação em nível nacional, aproximando-se da Aliança Liberal ${ }^{2}$. Segundo a autora, a esperança de romper com a conjuntura local se tornou realidade com a deflagração da Revolução de 1930.

Fruto dos grupos opositores locais, o político Pedro Ludovico Teixeira foi nomeado interventor em Goiás pelo Governo Provisório (1930-1934). Durante esses anos, Teixeira reproduziu o ideário varguista e, para confirmar seu compromisso, recuperou um antigo projeto local: a transferência da capital do país. Tal atitude consolidou o discurso do Governo Federal localmente, uma vez que a nova capital representaria a queda da oligarquia caiadista e, ao mesmo tempo, se tornaria exemplo do sucesso do novo governo.

Palacín (1994) considera que a construção da nova capital não foi vista como gasto, e sim como investimento. Se os grupos dominantes goianos desejavam

\footnotetext{
1. A oligarquia da família Caiado teve seu início em 1883, com Antônio José Caiado (presidente de Goiás de 1883 a 1884, de 1892 a 1893 e em 1895, e ainda senador de 1896 a 1899). Foi interrompida apenas com a ascensão de Pedro Ludovico Teixeira após o Movimento de 1930, momento em que esse político foi nomeado interventor por Getúlio Vargas.

2. Coligação oposicionista de âmbito nacional constituída em agosto de 1929, formada por líderes políticos dissidentes dos estados de Minas Gerais e do Rio Grande do Sul. As personalidades envolvidas com a Aliança Liberal apoiaram a candidatura de Getúlio Vargas como presidente e de João Pessoa como vice nas eleições realizadas em $1^{\circ}$ de março de 1930.
} 
romper com o passado, foi necessário criar o novo por meio do discurso da modernização. Com a adoção deste, marginalizou-se tudo o que havia acontecido antes, que se tornou velho, arcaico, atrasado e decadente. Para Chaul (1999), a nova capital concretizaria esse discurso, em que prevaleceriam a integração das regiões e o avanço do progresso para o interior. Para os goianos, uma nova capital se relacionava com o desenvolvimento econômico, social e cultural e, acima de tudo, representaria maior pertencimento à nação.

Com o intuito de concretizar essas ideias, foi elaborada uma propaganda mudancista junto à imprensa. Concomitantemente, optou-se por um modelo de cidade diferente da antiga capital colonial - Vila Boa de Goiás - e, para isso, adotou-se uma arquitetura próxima dos padrões da modernidade. No que se refere à concepção de cidade moderna, Ferraz (1996) considera que o espaço urbano não deveria servir apenas para acomodar as pessoas em um habitat, mas, também, para inseri-las dentro de uma vida social eficiente. Segundo esse autor, as cidades são produtoras de personalidades, pois buscam refletir a sociedade que abrigam (FERRAZ, 1996). Para Arrais (2013), a cidade moderna é um lugar privilegiado para a proliferação de discursos e a construção de imagens, de pessoas e objetos, os quais se tornam símbolos espaciais. Pautados nas posições desses autores, entendemos que o projeto arquitetônico da nova capital deveria representar as modernas exigências da época, já que ela deveria construir uma sociedade moderna no interior do país.

De acordo com Hélio Rocha (2003), os jornais contribuíram para a construção dessa imagem. Quando o espaço em que seria erguida a nova capital foi definido, o jornal O Social promoveu um concurso - lançado em 5 de outubro de 1933 - para a escolha do nome da cidade. O curioso é que Goiânia não estava entre as sugestões mais votadas. Para Souza (2002), o nome foi escolhido devido a seu apelo simbólico, por resgatar a interação entre o tradicional e o moderno. Desta forma, Goiânia seria a Nova Goiás, expressão do afastamento da resistência à modernização, e, simultaneamente representaria o prolongamento da história de Vila Boa de Goiás e da coletividade goiana (SOUZA, 2002).

Com o início das obras e a municipalização de Goiânia em 1935, foi criado o Departamento de Propaganda e Expansão do Estado de Goiás (DPEEG). Joaquim Câmara Filho foi nomeado para a direção desse órgão, que tinha como prioridade divulgar as decisões políticas do governo e prestar informações sobre as possibilidades econômicas da nova capital e suas conexões com o ideário varguista.

O projeto urbanístico foi baseado no estilo radiocêntrico, de modo que ruas e avenidas convergiam para o centro. Esse plano foi dividido em setores central, norte, sul e oeste -, por sua vez subdivididos em zonas. Os prédios públicos e a residência oficial foram reunidos em uma praça central localizada na parte alta da cidade. A análise do projeto torna visível a noção de cidade-jardim. 
Nele, áreas verdes se destacam em relação aos espaços reservados para edificações, avenidas e ruas. No que se refere à edificação da capital, os idealizadores priorizaram a construção dos prédios do Palácio do Governo e do Grande Hotel. A Figura 1 mostra uma ilustração divulgada pelo governo em 1935, a qual representa muito bem a ideia radiocêntrica e a de cidade-jardim.

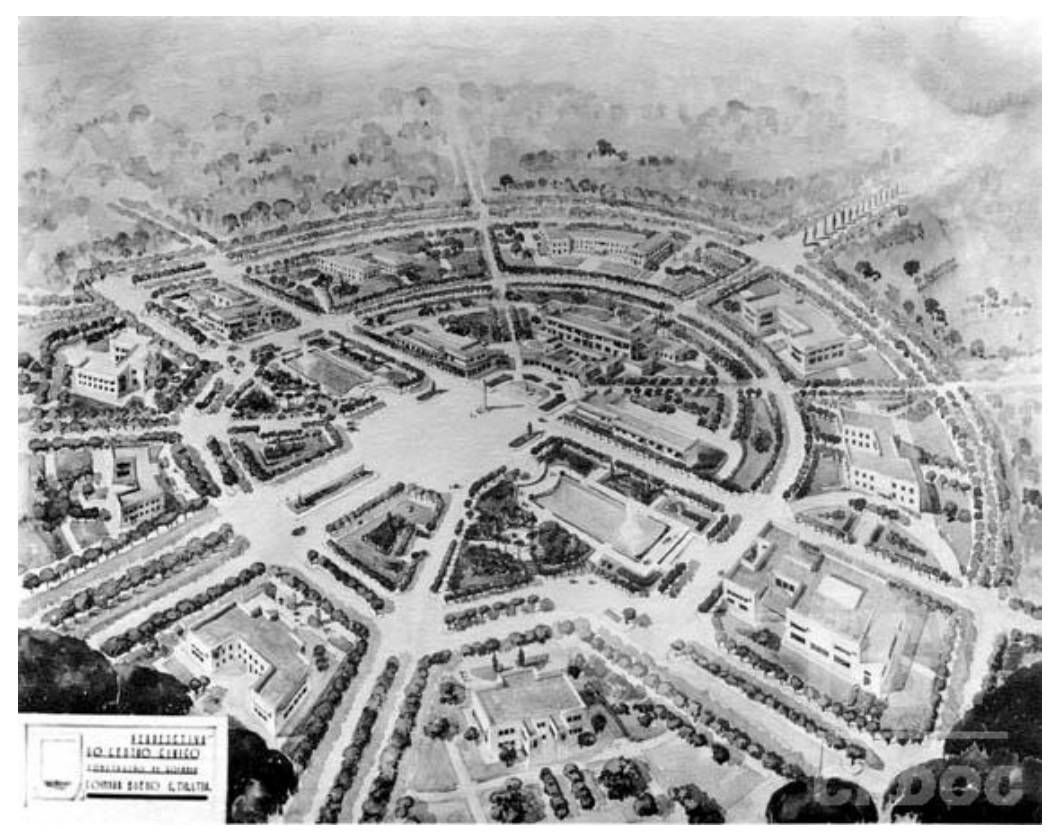

Figura 1. Ilustração do Plano Urbanístico de Goiânia (1935)

Fonte: Acervo do Centro de Pesquisa e Documentação de História Contemporânea do Brasil-Fundação Getulio Vargas (CPDOC-FGV).

Apesar dessas prioridades, algumas casas foram construídas para atrair moradores. Os estilos variavam entre o clássico, o eclético (mistura de barroco e clássico), o normando e o art déco, este último escolhido para os prédios públicos. Ao adotar o estilo urbanístico que caracterizava os centros urbanos modernos, os arquitetos reforçaram os elos entre o projeto modernizador local e a ideia de progresso adotada pelo Governo Federal.

Diante da dificuldade de circulação de notícias e informações na nova capital, o Governo Estadual concedeu a Joaquim Câmara Filho - diretor do DPEEG - licença para a publicação do jornal $O$ Popular no dia 3 de abril de 1938. O jornal, que circulava às quintas e aos domingos, era gerenciado por Jaime Câmara ${ }^{3}$

3. Irmão de Câmara Filho, Jaime Câmara se tornou - em 1932 - revisor da Imprensa Oficial e, em 1934 fundou a Associação Goiana de Imprensa. 
e dirigido pelo próprio Câmara Filho, ${ }^{4}$ e contava com a colaboração de Vicente Rebouças. ${ }^{5}$ Consideramos esse jornal um veículo de informação fortemente ligado ao poder político local, uma vez que seus proprietários mantinham laços com Pedro Ludovico desde o Movimento de 1930. Na Figura 2, é possível ver a página do primeiro número do periódico.

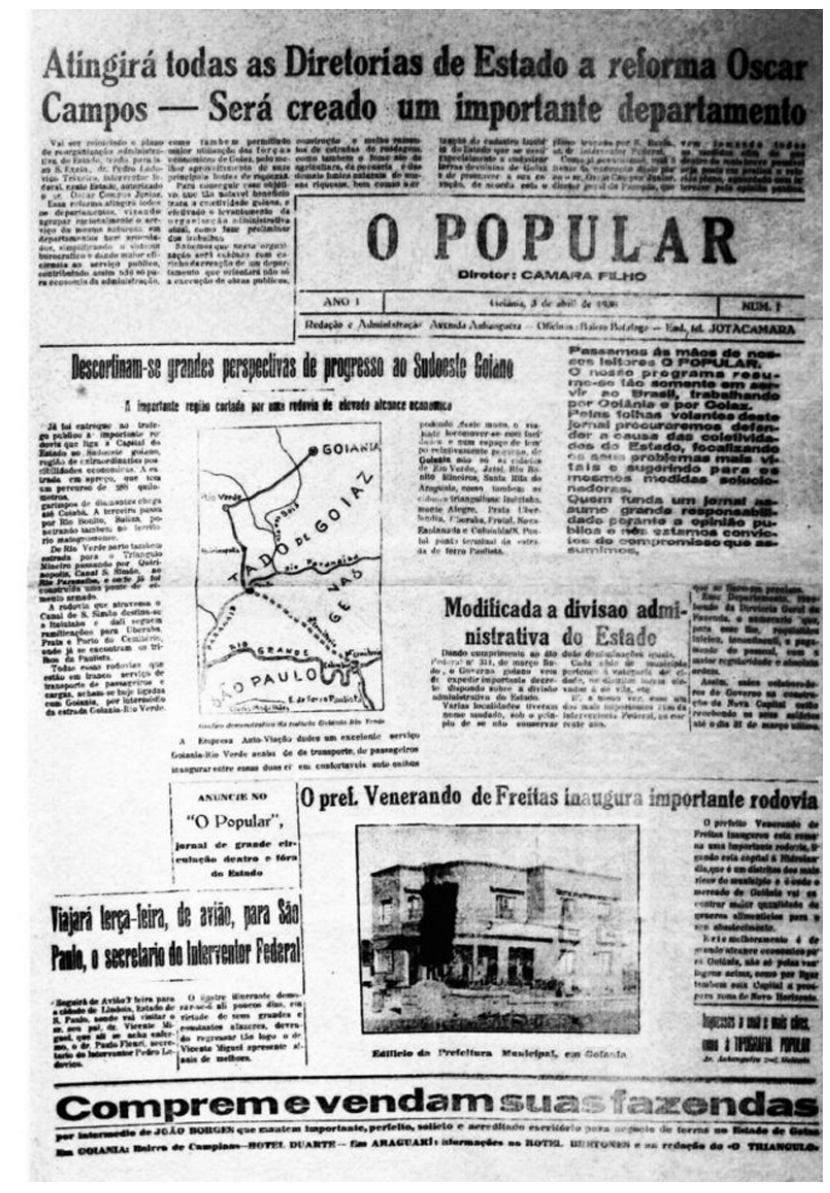

Figura 2. Primeiro número do jornal O Popular (1938)

Fonte: Acervo do jornal O Popular.

Na primeira página, os redatores noticiaram a reforma administrativa de Oscar Campos e a criação de novos departamentos. Também foi divulgada a manutenção de estradas que poderiam trazer novas perspectivas de progresso ao

4. Durante o Movimento de 1930, Câmara Filho recebeu a patente e logo depois foi nomeado um dos comandantes da força revolucionária goiana. Com a ascensão de Ludovico ao cargo de interventor goiano, no ano de 1932, foi nomeado prefeito de Pires do Rio e de Porangatu. A partir de 1935, dirigiu o DPEEG.

5. Vicente Rebouças foi o último dos irmãos Câmara a chegar a Goiás. Em 1935, junta-se a eles nos trabalhos gráficos e fica responsável pela divulgação do periódico nas cidades e no interior. 
sudoeste goiano, as quais ligariam a nova capital à cidade de Rio Verde. A viagem do secretário do interventor federal para São Paulo, a inauguração de uma nova rodovia, o anúncio de compra e venda de fazendas e uma fotografia do edifício da Prefeitura Municipal de Goiânia completaram as notícias da primeira página do primeiro exemplar do periódico.

Essa edição inicial foi composta de quatro páginas e uma tiragem de três mil exemplares, enviados para diversas cidades goianas. Vale lembrar que, segundo o Censo de 1940, Goiânia somava 48.166 habitantes, o que não era pouco para uma cidade que tinha pouco mais de seis anos. No discurso em comemoração ao cinquentenário de O Popular, Jaime Câmara Jr. (1988, p. 4) rememorou o objetivo inicial do jornal: divulgar uma sociedade que se desenvolveu e se modernizou. Essa afirmativa estabeleceu a associação entre a história do jornal e a da capital goiana. Nas palavras do filho do ex-gerente do diário, o jornal sempre buscou solucionar os problemas que impediam o progresso de Goiás. Essas palavras evidenciam a construção de uma memória - cinquenta anos depois - que fortaleceu os elos entre a criação do jornal, o alinhamento ao governo de Pedro Ludovico na década de 1930 e a história da cidade de Goiânia.

Em uma sociedade que dá prioridade à escrita, o interesse histórico pelas informações divulgadas pelos jornais promove a compreensão das experiências dos indivíduos e grupos. Apesar dessa especificidade, é preciso chamar atenção para o fato de que o jornal reproduz parcialmente tais experiências, uma vez que os grupos detentores do poder trabalham para convergir, não apenas seus interesses, mas os enunciados por meio dos quais estes serão consumidos e incorporados pelo leitor. Com base nas concepções de Sodré (1966), Marcondes Filho (1989) e Luca (2008), entendemos que o jornal O Popular surgiu com três funções: i) divulgar as ações do Governo Estadual; ii) informar sobre as possibilidades econômicas de Goiânia; e iii) construir uma versão única sobre a nova capital. Por essas razões, ele se constitui em fonte privilegiada para discutirmos as estratégias que a imprensa e o poder público construíram para representar simbolicamente a nova capital.

No próximo tópico, será apresentado o modo como O Popular contribuiu para a formação dessa nova paisagem urbana. A análise das notícias por ele veiculadas é significativa, pois reflete os movimentos da sociedade no espaço urbano, compreendido como uma realidade de funcionamento descontínuo, um mosaico de relações, de formas e sentidos (SANTOS, 1988). A soma de resíduos do cotidiano editados nas páginas desse jornal será utilizada para destacar alguns fatos que se tornaram notícia. Acreditamos que esse recurso nos permite discutir a reconstrução parcial de uma realidade urbana ainda em construção e perceber os movimentos econômicos, políticos, culturais e comportamentais divulgados pelo diário. 
3. O jornal O Popular e a construção de Goiânia: lazeres, edificações e o Batismo Cultural

Goiânia dispunha de pouquíssimas formas de divertimento nos primeiros anos. Hélio Rocha (2003) ressalta que elas se resumiam a filmes exibidos no Cineteatro Campinas, jogos de futebol, carnaval de rua e festas juninas. Concomitantemente às parcas atividades de lazer, a recém-capital contava com um número reduzido de habitantes, em sua maior parte moradores do Setor Campinas. ${ }^{6}$ Em face dessa situação, $O$ Popular promoveu uma atmosfera de entretenimento na nascente capital.

Os jogos de futebol que já haviam sido jogados há semanas, até meses, eram comentados exaustivamente na seção esportiva, estratégia que demonstra como o ordinário deixa de sê-lo ao ser apresentado como extraordinário pelo corpo editorial. A estratégia de transformar o ordinário em notícia era crônica, em especial para tornar públicas outras atividades de entretenimento, como a inauguração de uma sorveteria. A título de exemplo, cita-se a inauguração da Sorveteria Vera Cruz. Curiosamente, os comentários não estavam voltados para a nova opção de lazer, mas para as "máquinas modernas" e sua "considerável capacidade de produção" (SORVETERIA..., 1938, p. 3). Como expressão dos ares de modernidade, os comentários fazem referência à dinamização da produção. A aquisição de outros equipamentos "modernos" estava presente em várias notícias, como a compra de uma máquina de gelo por um bar, de um equipamento de raio $\mathrm{X}$ por um consultório odontológico ou a máquina de pautar adquirida pelo próprio $O$ Popular.

A forma como essas notícias eram dadas pode ser entendida como uma das estratégias utilizadas pelo corpo editorial, as quais estabeleciam o distanciamento perante o atraso, o passado e o antigo, palavras associadas à antiga-capital. Ao reforçar simbolicamente esse distanciamento, as notícias faziam com que o leitor se sentisse em uma cidade moderna. Desse modo, o leitor, e, concomitantemente, o morador da cidade de Goiânia, compartilha experiências da comunidade nacional. O goianiense, portanto, poderia experimentar os mesmos comportamentos e objetos que um morador do Centro-Sul.

Segundo Hélio Rocha (2003), antes da inauguração do Automóvel Clube, os bailes e as festas eram realizados no Grande Hotel. Embora tenha sido aberto para o réveillon de 1937, somente três semanas mais tarde é que ele foi inaugurado.

6. A cidade de Campininha das Flores foi extinta e transformada em bairro da nova capital, de acordo com o Decreto estadual $n^{\circ}$ 327, de 2 de agosto de 1935. GOVERNO DO ESTADO DE GOIÁs. Decreto $n^{\circ} 327$, de 2 de agôsto de 1935. Ficam fundidos em um único os atuais municípios de Campinas, Hidrolândia e parte dos territórios dos Anápolis, Bela Vista e Trindade que passarão a constituir o Município de Goiânia, com séde na cidade do mesmo nome, óra em construção no município de Campinas, desaparecido por efeito deste decreto, o mesmo de que fala o art. $5^{\circ}$ do projeto da Constituição do Estado, já aprovado, nessa parte, em redação final. Diário Oficial: Goiás, 3 ago. 1935. [Foi mantida a grafia original do documento, disponível em: https://legisla.casacivil.go.gov.br/api/v1/arquivos/12587. Acesso em: 11 nov. 2021.] 
Esse hotel foi incluído no plano urbanístico da capital com o propósito de acolher investidores convidados pela administração pública. Parte do projeto urbanístico, a ideia de edificá-lo foi do arquiteto-urbanista Atílio Corrêa Lima, e sua construção ficou a cargo da Coimbra Bueno (ROCHA, D., 2012). Na Figura 3, tem-se uma fotografia de 1937, tirada do alto do Palácio das Esmeraldas - sede do governo de Goiás -, localizado na Praça Cívica.

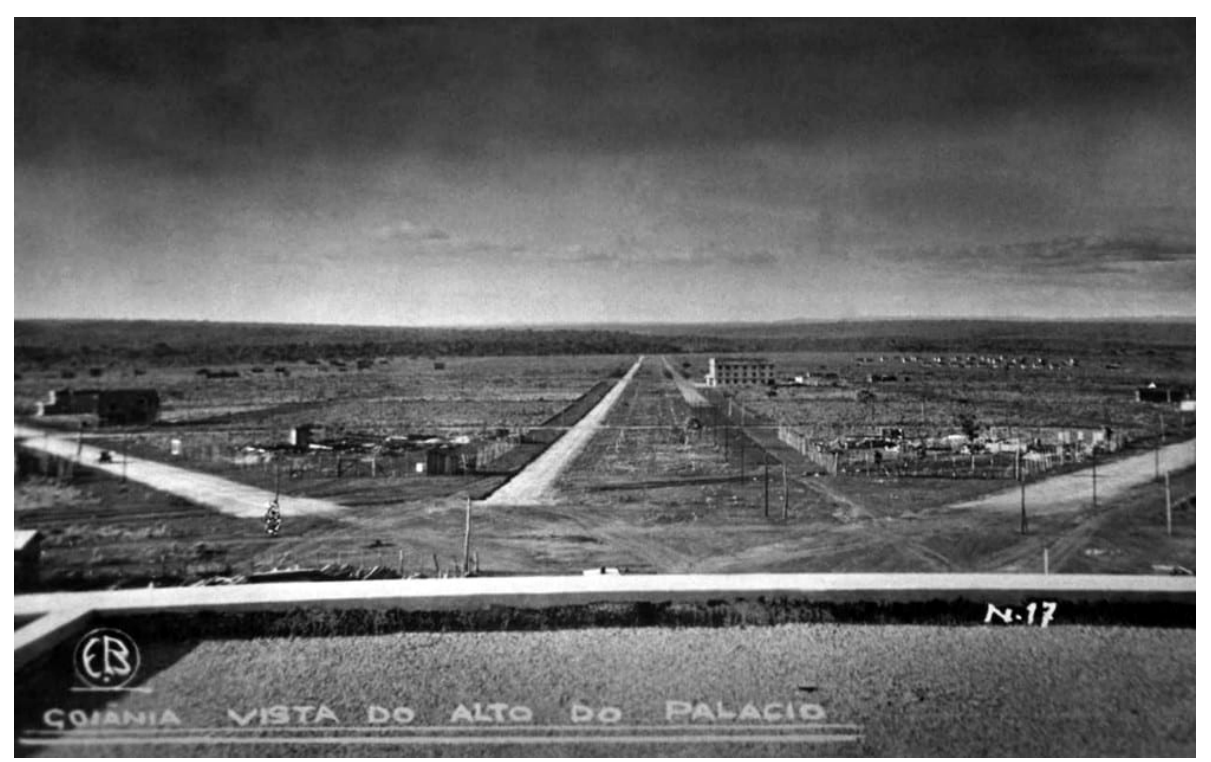

Figura 3. Vista de Goiânia (1937)

Fonte: Divisão de Patrimônio Histórico da Secretaria de Cultura. Foto de Eduardo Bilemjian.

Ao fundo - no centro à direita da fotografia -, ergue-se um prédio solitário: trata-se do Grande Hotel, localizado na avenida Goiás com a Rua 3. Construído sob a influência art déco, esse edifício foi pensado para receber personalidades ilustres que visitariam a recém-inaugurada capital. Em $O$ Popular, encontramos a coluna intitulada "Os que chegam e os que saem", na qual os redatores mantinham o leitor informado a respeito da quantidade e da qualidade das pessoas que visitavam a nova cidade.

Com a finalização das obras do Automóvel Clube, os bailes deixaram de acontecer no Grande Hotel. Os "bailes de chita” e as “festas joaninas” realizados no novo espaço recebiam destaque nas manchetes de $O$ Popular. As notícias das festas eram acompanhadas do noticiário sobre a remodelação pela qual passavam os salões do estabelecimento. Em um primeiro momento, a preocupação com o divertimento parece sobressair, mas as comemorações são deslocadas para segundo plano, visto que as melhorias na estrutura do clube tomaram maior repercussão na manchete. 
O Automóvel Clube, local onde se realizavam bailes carnavalescos, "festas joaninas", "bailes de chita” e outras festas promovidas pelo poder público, era símbolo de uma cidade onde quase não havia carros. Em 1942, surgem as notícias da possibilidade de mudança do nome do clube. Segundo o diário, a denominação não se justificava por motivos já conhecidos e outros que não são de domínio público. As fontes não são claras a esse respeito, mas a mudança do nome pode ser explicada por duas razões: i) a quase total ausência de carros na cidade e ii) a alta inadimplência nas quitações das ações. $O$ jornal sempre noticiava o atraso no pagamento dos títulos. Com a inadimplência, Pedro Ludovico foi obrigado a pedir ajuda financeira para Osvaldo Aranha, então ministro das Relações Exteriores. Segundo Hélio Rocha (2003), o ministro informou que o Governo Federal poderia conceder o auxílio desde que o clube investisse em hipismo. A alteração do nome para Jóquei Clube, conforme publicado, poderia influenciar a corrida de cavalos e incentivaria "o gosto pela criação de animais de raça e cultiva[ria] esse elegante gênero de esporte” (JÓQUEI..., 1942, p. 2).

As festas carnavalescas tomavam as ruas do Setor Campinas. No início de cada ano, o carnaval era a principal notícia e, após os festejos, o jornal resumia o que acontecera na coluna “O Carnaval que passou...”. Em uma delas, o redator comentou os "blocos que abafaram" na "Avenida 24 de outubro de um quilômetro de extensão" (CARNAVAL..., 1939, p. 4). Assim como noutras reportagens, repete-se a estratégia, ou seja, dar respaldo aos elementos referentes à modernização. Em meio às notícias sobre o sucesso do carnaval de 1939, a avenida 24 de Outubro recebeu maior destaque. Os redatores fazem questão de enfatizar que a celebração tomou "um quilometro de extensão" em linha reta da avenida, algo bastante amplo para os padrões da antiga capital. Com esse recurso, o diário reforçou representações que faziam com que o leitor se sentisse pertencente a uma cidade moderna, uma vez que as avenidas em linha reta se tornaram símbolos de cidades desse tipo.

As edições analisadas traziam notícias sobre a construção de prédios modernos em áreas fora do plano diretor da capital. As transformações na praça Joaquim Lúcio no Setor Campinas são recorrentes, em particular a demolição de prédios tidos como "antiquados". Segundo o jornal, "esta[s] demoliç[ões] procura[m] remodelar Campinas e aproximá-la do estilo da nova Capital” (REMODELAÇÃO..., 1938, p. 1). Ao definir o art déco como modelo arquitetônico, o corpo editorial de O Popular promoveu uma sobreposição efetiva da capital em relação à extinta cidade de Campininha das Flores, para onde esse estilo deveria ser transplantado. Tais alterações não tinham a finalidade de atingir todo o antigo município, pois as demolições pretendiam alterar apenas a arquitetura das edificações próximas à praça Joaquim Lúcio. 
Em 24 de maio de 1938, O Popular informou que o governo municipal havia decretado a proibição da construção de prédios ou a realização de reformas que pudessem provocar desacordo em relação à planta da capital. Desta forma, nenhuma obra poderia ser feita sem aprovação prévia. Então, para melhor enquadrar o Setor Campinas ao estilo arquitetônico de Goiânia, foram demolidos o Hotel Duarte e outras propriedades particulares. Essas ações, segundo o jornal, foram tomadas pelo prefeito Venerando de Freitas Borges com o intuito "de embelezar o bairro mais importante de Goiânia[,] que é Campinas” (CAMPINAS..., 10 jul. 1938, p. 3).

Essa notícia nos põe diante da anexação material e simbólica da antiga cidade de Campininha das Flores ao plano urbanístico de Goiânia. Esse exemplo expressa a influência do ideal de modernidade, tendo em vista que as propostas de modelos arquitetônicos modernos foram sobrepostas às construções consideradas ultrapassadas. As remodelações na praça Joaquim Lúcio, no Setor Campinas, foram exemplos da contínua construção da capital, da atuação e da intervenção do poder público nas formas de perceber a cidade. Essas ações objetivavam modernizar não só o espaço urbano, como também as vivências e o comportamento das pessoas.

A fim de celebrar a consolidação urbana e política de Goiânia, organizou-se no dia 5 de julho de 1942 a inauguração oficial da cidade, data localmente conhecida como Batismo Cultural. Souza (2002) considera que, ao demarcar simbolicamente o controle humano sobre o espaço, a inauguração não refletiu apenas a aspiração do regionalismo, mas igualmente um desejo do governo e de seus institutos - sobretudo do Instituto Brasileiro de Geografia e Estatística (IBGE) - de inserir Goiânia simbolicamente no projeto nacional estado-novista.

O objetivo de formalizar a consolidação de Goiânia tomou corpo no início de 1942. Em telegrama (SOARES, 1942) enviado no dia 16 de janeiro de 1942 ao interventor goiano, o presidente do IBGE - Fábio de Macedo Soares Guimarães - defendeu a necessidade de promover a inauguração oficial da capital. Nesse telegrama, defende-se a ideia de que a inauguração poderia inserir mais efetivamente o estado de Goiás na marcha nacional e, ao mesmo tempo, no movimento de progresso intelectual e cultural estado-novista. Os comentários jornalísticos feitos com base nas palavras de Guimarães guardam referências ao ideário do progresso e da modernização, visto que o Batismo Cultural de Goiânia refletiria a "interiorização das forças civilizadoras, na continuidade de sua Marcha para o Oeste” (INAUGURAÇÃO..., 1942, p. 1).

De acordo com Souza (2012), na celebração oficial tentou-se mesclar os progressos científicos e os aspectos culturais da região. Para os idealizadores dos festejos, esse conjunto de prerrogativas seria capaz de modificar a imagem de Goiás fora do estado; eles acreditavam que a intelectualidade, a diversidade cultural e 
a procura pela brasilidade aproximariam Goiânia do restante do país. De acordo com o corpo editorial do O Popular, a inauguração provaria que o "surto de progresso modificou a imagem de Goiás” (PREPARATIVOS..., 12 fev. 1942, p. 2). Souza (2012) acrescenta que a inauguração apresentou ao público uma composição única sobre os significados da cidade para o estado e para o Brasil. Na Figura 4, apresenta-se o fôlder comemorativo.

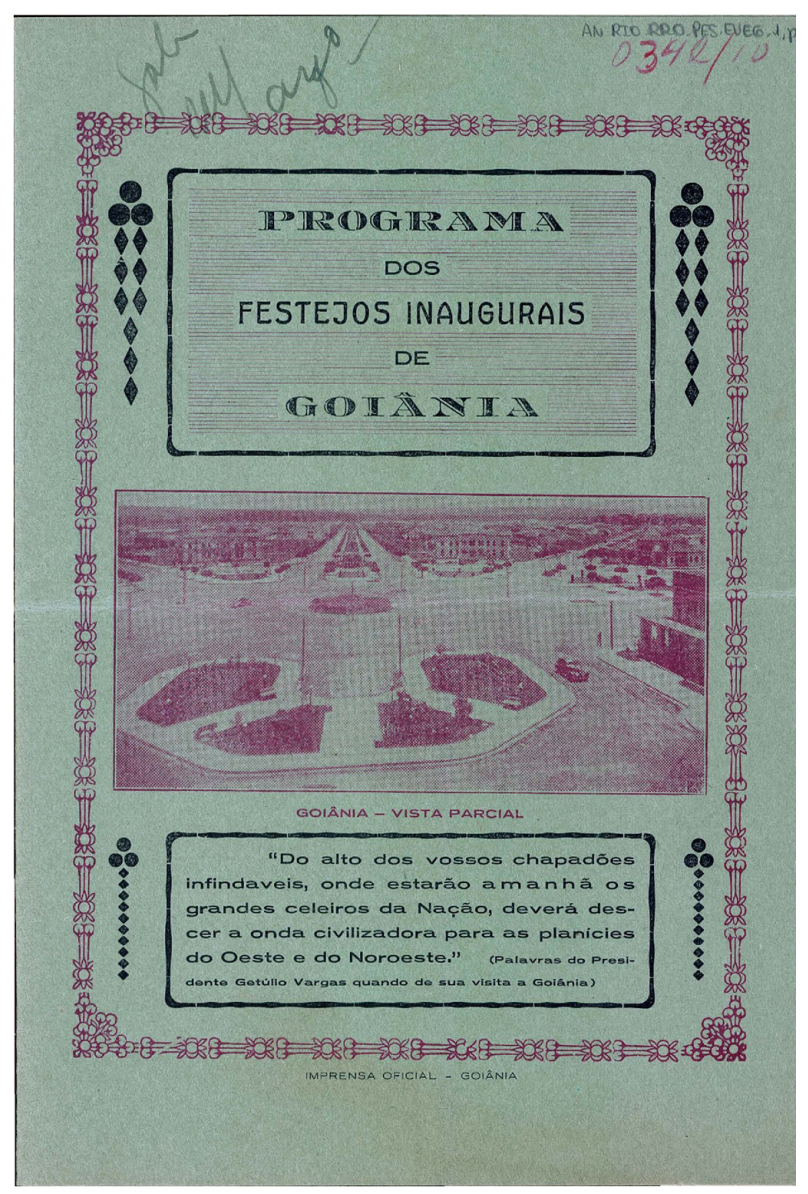

Figura 4. Programa dos festejos inaugurais de Goiânia (1942) Fonte: Arquivo Nacional.

No que se refere às comemorações, Osvaldo Aranha reforçou o papel desempenhado pelo diretor de $O$ Popular e pelo interventor Pedro Ludovico na concretização do plano político de Getúlio Vargas. O jornal goiano transcreve a carta de Aranha (1942, p. 4), na qual ele agradece

[...] a moção do Senhor Joaquim Câmara Filho sobre minha participação na construção da cidade de Goiânia, que, graças ao Interventor Pedro Ludovico, se afirma como uma realização da capacidade criadora dos brasileiros, como um marco da nossa obra civilizadora. 
Vislumbra-se nessas palavras a notória tentativa de relacionar a nova capital com o projeto estado-novista. Para a inauguração oficial, o Departamento Estadual de Imprensa e Propaganda (Deip) solicitou a todos os 52 prefeitos goianos que realizassem - no mesmo dia e hora - uma cerimônia. As comemorações nos municípios fariam referência ao projeto civilizador representado pela construção de Goiânia. Durante a inauguração, percebida como ritual local e coletivo, haveria uma concentração escolar e uma sessão cívica seguida da fala do relator de cada município "sobre a obra administrativa do Interventor Pedro Ludovico" e, também, sobre "a importância significativa da fundação de Goiânia para o futuro do Estado e do Brasil” (PREPARATIVOS..., 14 jun. 1942, p. 3).

No dia do "Batismo", o assunto ocupou toda primeira página de $O$ Popular, como se vê na Figura 5.

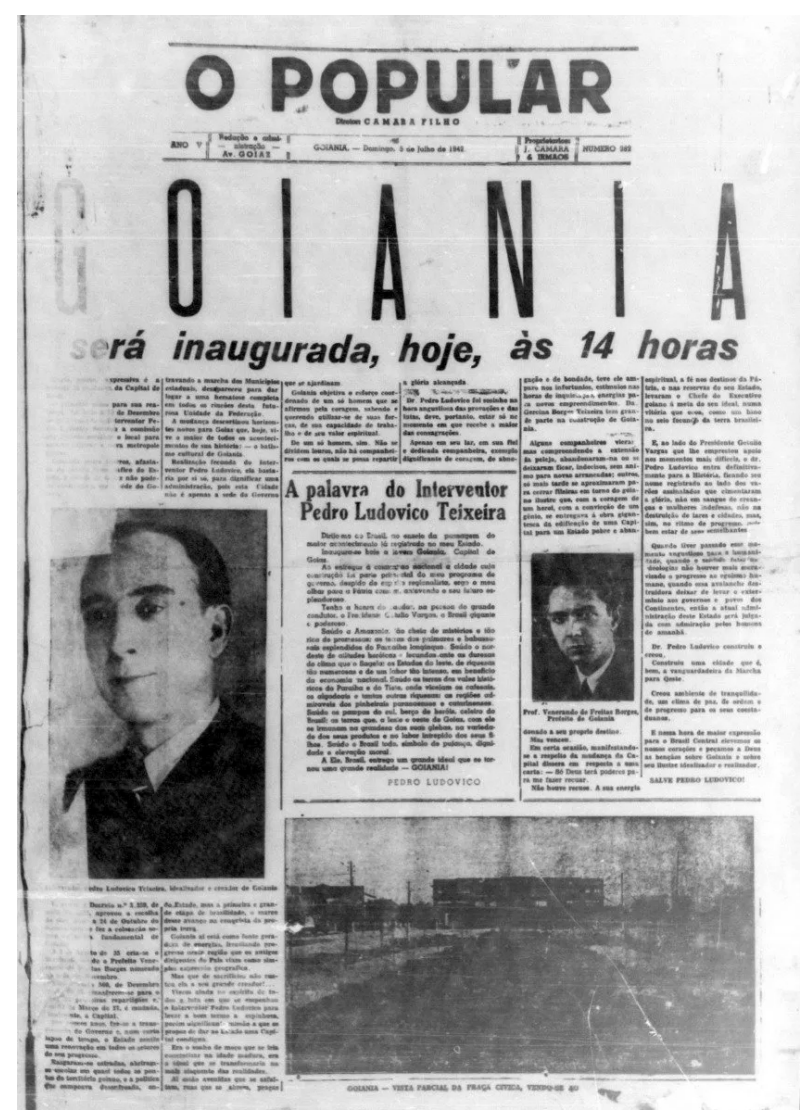

Figura 5. Primeira página de O Popular (1942)

Fonte: Acervo do jornal O Popular.

Na primeira página, foram colocadas as fotos do interventor e do prefeito de Goiânia, além de uma manchete com letras garrafais: "Goiania será inaugurada, hoje, às 14 horas”. A imagem da Figura 6 retrata a participação popular na celebração dos festejos. 


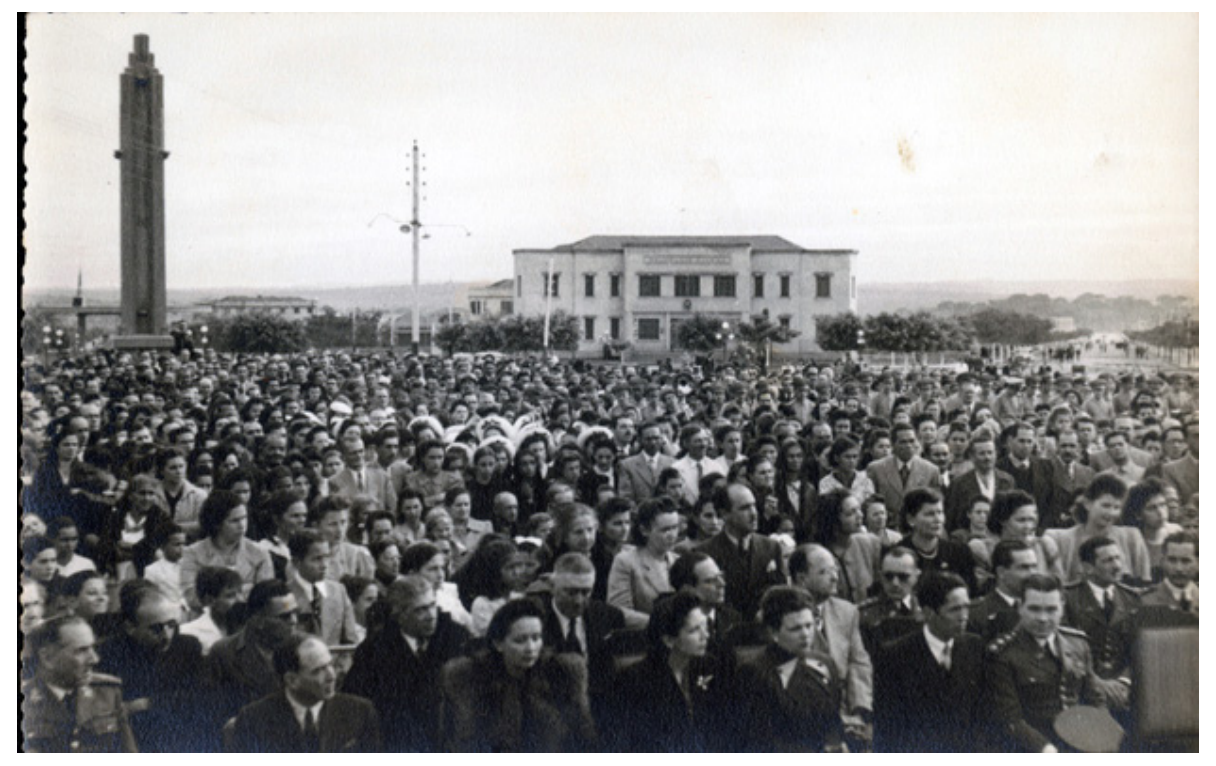

Figura 6. Convidados e populares durante o Batismo Cultural de Goiânia (1942) Fonte: Secretaria de Cultura de Goiânia.

Após a realização dos festejos, o Deip recebeu telegrama confirmando a participação dos 52 municípios. O jornal comentou a solidariedade regional e exaltou a realização simultânea de festas em outras cidades: "a comemoração não ficou restrita apenas para a capital” (NOTÍCIAS..., 1942, p. 2). Tem-se assim a construção de um discurso decorrente da produção de uma ideia de coletividade regional aglutinada pelo valor simbólico de Goiânia.

Terminadas as comemorações, permaneceram os discursos exaltando os interesses nacionais e um projeto que associava a construção de Goiânia ao futuro, como se essa predestinação fosse parte de uma reivindicação histórica. Segundo o discurso jornalístico, o Batismo Cultural de Goiânia foi o maior reflexo da coletividade nacional, da herança histórica das antigas bandeiras paulistas e de um ideal civilizador estado-novista. Assim:

Os povos têm seus homens, seus ídolos, pelos quais procuram moldar seus atos, dirigir seus passos e firmar suas convicções. Goiânia não é fruto do impulso momentâneo ou de um capricho político. É a concretização de um ideal secular tantas vezes sentido e lembrado, mas que circunstâncias não permitiram se realizasse (EDITORIAL, 1942, p. 1).

Muito mais que informar, a utilização política da imprensa procurou reconstruir uma realidade resultante da junção de fatores que explicavam determinado fato. A data do nascimento cultural de Goiânia foi tomada como o marco da integração nacional de Goiás. Ao ler as páginas de $O$ Popular, depreende-se que o 
ritual de incorporação à nação representou a concretização da anexação do Brasil central à nacionalidade em busca da brasilidade (SOUZA, 2012). Essa incorporação foi engrandecida pelos discursos proferidos durante as comemorações, em que o domínio intelectual do espaço acompanhou a ocupação do "vazio" que impedia o avanço do país (id., ib.). Na base dessa formação discursiva, registra-se a associação entre a reinterpretação do passado, a exaltação da atuação de Pedro Ludovico e o projeto de futuro.

Apoiados nessas considerações, defendemos que fatores econômicos, políticos e simbólicos estavam presentes no discurso jornalístico que transformou o cotidiano da nascente capital em notícia. No próximo tópico, descreve-se como a edificação da estátua do bandeirante reforçou a ação do Estado interventor e, ao mesmo tempo, consolidou simbolicamente a aproximação da cidade ao projeto estado-novista. Essa análise histórica será importante para identificarmos como a imprensa contribuiu para a construção simbólica do cotidiano e, paralelamente, noticiou as transformações pelas quais passou a cidade.

4. O discurso de colonização interna no estado de Goiás: a campanha prómonumento aos bandeirantes

Ao final de 1939, Vargas visitou Goiânia. Seria o primeiro chefe da nação a visitar o Brasil central, gesto simbólico que representou o avanço do Governo Federal rumo ao interior (CAPELATO, 1998). Ainda que o progresso não tenha vindo da forma como foi mitificado, a visita do presidente não deixou de ser um meio de afirmar a brasilidade e a necessidade de colonizar o interior. Em relação a essa visita, Capelato (1998) nos lembra de que os órgãos de divulgação concluíram que Vargas entrou em contato direto com a população das regiões mais atrasadas do país.

O presidente desembarcou em Goiânia em 5 de agosto de 1940. Nesse dia, O Popular descreveu toda a trajetória que ele percorreria. Houve um desfile escolar, com a participação dos recrutas do Tiro de Guerra, tudo em conformidade com o ritual de cerimônia. Capelato (1998) afirma que as festas oficiais estado-novistas tinham ampla participação popular, até porque a presença obrigatória de vários setores - escolas, Forças Armadas, Corpo de Bombeiros, Polícia, bandas, corais, grupo de dança e de teatro, escoteiros e sindicatos - garantiu um número representativo de pessoas. Vargas esteve no ato de lançamento da pedra fundamental do estádio de futebol na avenida Paranaíba e, o principal, no ato solene de lançamento da campanha "Marcha para o Oeste" nos salões do Automóvel Clube, cuja sede foi inaugurada no mesmo dia.

No pronunciamento de inauguração da associação cívica "Cruzada Rumo ao Oeste”, Vargas falou sobre a necessidade de a região acompanhar o crescimento do Brasil, bem como de "localizar no centro [...] do país poderosas forças capazes 
de irradiar e garantir a nossa expansão futura” (VARGAS, 1943, p. 149). Em seu pronunciamento, o presidente declarou que o governo nacional tem o "propósito de impulsionar o Brasil como um todo orgânico e equilibrado" para eliminar as "ilhas, entremeadas de espaços vazios” (id., ib.). Essas palavras demonstram que o nacionalismo e o progresso econômico se fundiam no discurso do projeto nacional, que deveria fazer com que "as fronteiras econômicas coincid[issem] com as fronteiras políticas. Eis o nosso imperialismo [...] um expansionismo, que é o de crescermos dentro de nossas próprias fronteiras” (id., ib.). Por fim, em sua fala. Vargas (id., ib.) enfatizou que, "se politicamente o Brasil é uma unidade, não o é economicamente", e, por essa razão, a união entre a fronteira política e a fronteira econômica consistia no grande desafio da nação brasileira.

Ao discursar no palácio do governo em Goiânia no dia 7 de agosto, o presidente fez uma breve análise do passado brasileiro: sob "o Império e a primeira República, crescemos [...] à orla das águas atlânticas [...] voltado para fora”, mas, com "o advento do Estado Novo [...] a civilização brasileira tomou o caminho dos paralelos”, porque "o vosso planalto é o miradouro do Brasil” (VARGAS, 1943, p. 149). O chefe da nação defendeu a região Centro-Oeste como o lugar de ocupação histórica das bandeiras paulistas e o caminho para constituir a base de um novo plano político-econômico. E ratificou que o programa "Rumo ao Oeste" representaria o "reatamento da campanha dos construtores da nacionalidade, dos bandeirantes e dos sertanistas" (id., p. 151).

Levada pela onda de contínua construção da paisagem urbana e pelo projeto ideológico estado-novista, alguns goianienses eram da opinião de que a nova capital necessitava de um monumento representativo do espírito da colonização do centro do país. O bandeirante foi escolhido como o personagem-símbolo para representar tais anseios e justificar a interiorização, a integração e a unificação nacional. Em 1938, a Faculdade de Direito de Goiânia - com o apoio do Centro Acadêmico XI de Agosto da Faculdade de Direito de São Paulo - iniciou a articulação de doações para erigir um monumento em homenagem ao dito herói. Esses movimentos foram noticiados em $O$ Popular com o título “Campanha pró-bandeirante”. As notícias eram favoráveis a uma homenagem à memória dos bandeirantes, a ser representado por Bartolomeu Bueno da Silva (1672-1740), como uma "justa e sincera homenagem que se possa prestar aos heroicos formadores da Nacionalidade” (CAMPANHA..., p. 2).

Para a construção do monumento, o interventor de São Paulo - Ademar de Barros - doou trinta contos como auxílio à construção da estátua, que "seria erigida na parte central da cidade de Goiânia” (DOAÇÕES..., 1938, p. 1). Esse teria sido, conforme se lê no diário, um gesto simbólico de boa vontade e, mais, a construção de um marco simbólico - tradicionalmente paulista-em um centro urbano no interior. 
Para o corpo editorial do jornal, esse ato fortaleceria os sinais de identidade e aproximação com as cidades mais desenvolvidas. Para reforçar esse intento, o dr. Manoel Victor, recorrentemente mencionado no jornal, fala à Rádio Bandeirante, e seu pronunciamento, transcrito nas páginas de $O$ Popular, reforçou o propósito de valorizar os bandeirantes para justificar a construção do monumento:

Morrem os idealistas, mas, não morrem as ideias. Morrem os mártires, mas ficam imortais seus exemplos [...] puseram os seus arrojos em holocausto à pátria, mas conseguiram essa pátria para nossa glória! E a grande lição ficou dentro da raça como uma apoteose! (VICTOR, 1938, p. 2).

Como é possível entrever pela leitura desse fragmento, foi reforçada a interpretação na qual a formação do território e a essência da raça brasileira foram encontradas no bandeirantismo do século XVIII. A audácia dos bandeirantes também foi comparada ao espírito que sustentou as ações revolucionárias no presente, casos da Revolução de 1930 e da Decretação do Estado Novo, em 1937. Já em nível regional, esse espírito foi associado à transferência da capital de Vila Boa de Goiás para Goiânia.

Passados quatro anos da campanha pró-bandeirante, a estátua em homenagem a Bartolomeu Bueno da Silva foi esculpida em bronze pelo artista plástico Armando Zago7 e inaugurada em 9 de novembro de 1942 (Figura 7).

Em 1942, ano do Batismo Cultural da cidade, Zago foi contratado para construir a estátua em homenagem aos bandeirantes. Segundo Jordanna Silva (2020, p. 14-15), o conjunto estético da obra foi concebido por "Armando Zago, escultor italiano de carreira artística paulista, com destaque na arte funerária, conhecido como o artista da dor”. A autora afirma que o escultor não criou livremente uma imagem que representaria o bandeirante nem escolheu o lugar de sua fixação, e tampouco esteve relacionado ao financiamento e à escolha da homenagem, mas considera ser necessário rastrear "essa rede de agentes que faz acontecer o marco histórico, que inaugura a referência espacial no centro da cidade, o marco, o ponto focal na paisagem urbana” (SILVA, J., 2020, p. 15). Para Silva e Pinto (2019, p. 13), a construção desse monumento teve como atores "agentes públicos vinculados aos governos e alguns municípios paulista e goiano, bem como escritores, historiadores, diretores de museus, acadêmicos, estudantes e professores”.

7. Segundo Silva (2020, p. 153), "não houve concurso para seleção do escultor. A escolha foi, em alguma medida, arbitrária, feita por indicação e reconhecimento. No entanto, teve Armando Zago que se submeter à avaliação dos historiadores” para a elaboração da escultura. 


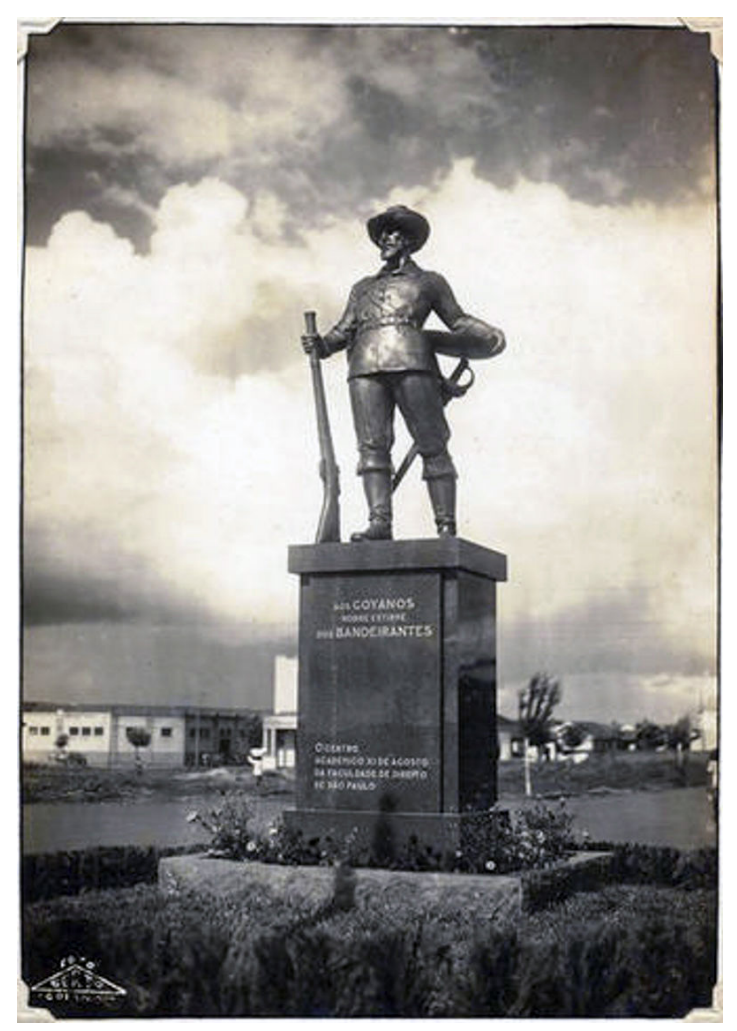

Figura 7. Fotografia do Monumento aos Bandeirantes em Goiânia (1942)

Fonte: Acervo do Centro de Informação, Documentação e Arquivo (Cidarq) da Universidade Federal de Goiás (UFG).

O exemplo da campanha pró-bandeirante nos permite concluir que O Popular se apropriou do suporte ideológico do Estado Novo. Ao associar o "mito bandeirante” à "unidade nacional”, o diário defendeu a necessidade de um monumento que representasse esse espírito. É explícito o jogo entre escrita, leitura e troca simbólica que proporcionou a exterioridade e a materialidade do discurso estado-novista. A relação entre linguagem/pensamento/mundo e a produção/reprodução/transformação de um enunciado é fundamental para entender a construção do discurso de incorporar o interior à nacionalidade, o qual se exteriorizou na construção do Monumento aos Bandeirantes. A expectativa dos defensores da campanha pró-bandeirante era de que, com o erguimento da estátua, poderiam se consolidar expressões como "imperialismo brasileiro", "agente construtor da nação" e "união das fronteiras”. O monumento em homenagem a Bartolomeu Bueno da Silva seria uma forma de consolidar a relação entre regionalismo, nacionalismo e o desenvolvimento econômico da nação, tendo nas bandeiras o exemplo mítico-histórico a ser seguido.

Para pensar sobre a importância desse monumento no imaginário local, fazemos uso da noção de "lugares de memória”, elaborada por Nora (1985). 
Para esse historiador francês, muito da memória nacional pode ser reforçada com monumentos deliberadamente erguidos por segmentos políticos, destinados a reforçar poderes e saberes sobre o passado e sobre as origens da nação desejada pelos grupos que apoiam essas ações. Um pouco mais alinhado a nossa análise estão Hobsbawn e Ranger (1997) e suas considerações a respeito das "invenções das tradições". De acordo com esses autores (1997, p. 9), a noção de "tradição inventada" pode ser entendida por um conjunto de práticas

[...] normalmente reguladas por regras tácitas ou abertamente aceitas; tais práticas, de natureza ritual ou simbólica, visam inculcar certos valores e normas de comportamento através da repetição, o que implica, automaticamente; uma continuidade em relação ao passado.

Levando em consideração os argumentos contidos em O Popular, a observação de Hobsbawn e Ranger (1997) nos auxilia no esclarecimento sobre a principal função do Monumento aos Bandeirantes construído em Goiânia, isto é, rememorar os supostos heróis do passado exaltados pelo poder local e nacional. De qualquer modo, é importante deixar claro que os apoiadores da construção desse monumento eram herdeiros de uma forma particular de idealizar o passado paulista - em outras palavras, de uma tradição estabelecida, solidificada já na década de 1910. Por outro lado, se nos debruçarmos na noção de invenção das tradições, é possível indagar: qual tradição não é inventada? O interessante não é pensar como essa tradição foi originada, e sim como ela transitou entre os campos histórico, político e artístico.

De acordo com Luiz Sérgio Duarte da Silva (2002), ao aproximar a construção da identidade goiana das representações do passado histórico dos paulistas, o discurso estado-novista fortaleceu a intenção de localizar no coração do país o reservatório da brasilidade. Esse processo pode ser entendido por meio do conceito de "regionalismo totalizante", ou seja, um símbolo regional - o bandeirante - que passou a representar toda a nacionalidade (COELHO, 2015). A reinvenção política do bandeirante cingiu-se ao domínio do destino, visto que Cassiano Ricardo - o principal ideólogo da campanha "Marcha para o Oeste" - defendeu em sua obra Marcha para Oeste: a influência da bandeira na formação social e política do Brasil (1940) que, sem o bandeirantismo, o Brasil não existiria! Daí nossa defesa da viabilidade do conceito de "regionalismo totalizante" para compreender a apropriação de símbolos regionais como suportes ideológicos para englobar as diversas regiões. Esse discurso regionalista foi predominante nos primeiros anos de fundação da cidade de Goiânia, tanto nas concepções simbólicas da modernidade como no tocante à 
continuidade política e econômica com a região Centro-Sul, e consolidou-se materialmente com a construção do Monumento aos Bandeirantes em Goiânia, com a adoção de um estilo moderno na edificação dos prédios públicos e com as formas pelas quais $O$ Popular noticiou o cotidiano urbano na capital.

\section{Considerações finais}

Como visto, o ideal de modernização adotado pela Era Vargas permeou o discurso da transferência da capital do estado de Goiás, a construção de Goiânia e as estratégias utilizadas pelo jornal $O$ Popular para noticiar o cotidiano da nova capital. Esse recorte temporal - de 1938 a 1942 - se relaciona, ainda, com as primeiras experiências na consolidação das relações sociais em Goiânia e com a construção contínua dos espaços urbanos. O leitor poderia questionar: se a relação do jornal com o espaço urbano seria o elemento responsável por determinar a guinada moderna da cidade, por qual motivo apontamos o alinhamento desta com o ideal de modernização estado-novista? $\mathrm{Ou}$, ainda, a consecução desse ideal varguista não independeria de $O$ Popular? As duas respostas convergem, ao pensarmos que a autonomia política local nesse contexto era bastante fragilizada diante da guinada autoritária do período, regime que utilizava a imprensa como um dos principais meios de controle e orientação da opinião pública.

Vale ressaltar também que as estratégias utilizadas pelo jornal O Popular possibilitaram a construção de uma realidade que se impôs ao novo morador, modificando e recriando as relações sociais. Na construção da imagem da cidade transmitida pelo jornalismo, é nítida a opção ideológica, em que se verifica que o jornal é um veículo de reprodução parcial da realidade. Ao ser consumida pelo público leitor, a notícia foi transformada em mercadoria, assim como o próprio cotidiano de quem a lia. Após a consolidação da transferência da capital, a cidade passou a ser imaginada não mais como a nova sede do governo, e sim como uma cidade inteiramente construída com base em um planejamento técnico, prático e midiático. Neste sentido, Goiânia tornou-se realidade por etapas progressivas de consolidação estrutural, política e simbólica.

Todo esse processo foi possível graças ao fato de que os diretores de $O$ Popular tinham fortes relações com o Governo Estadual, o que nos leva a entender que, além de ser representativo da imprensa noticiosa, o periódico pode ser entendido como um órgão de propaganda política das elites locais. Essa situação propiciou a divulgação das potencialidades da nova capital, mas também foi utilizada pelo Governo Federal como veículo de difusão de seu arcabouço ideológico, particularmente durante o Batismo Cultural de Goiânia e a construção do Monumento aos Bandeirantes. 
Como é possível perceber, a cidade de Goiânia - produzida simbolicamente pelo jornal $O$ Popular - foi concebida como um espaço de interações humanas e políticas, em que a política da notícia pretendeu inserir os moradores nos fenômenos históricos globais, como jogos de futebol, bailes, modernização dos espaços e inauguração de monumentos. Acreditamos que nosso estudo possibilitou a construção de novas narrativas sobre a história de Goiânia, que se distanciam das interpretações oferecidas por Palacin (1994), Chaul (1999) e Arrais (2013). Nossa originalidade se deve ao fato de que, diferentemente desses autores, abordamos o processo de sua construção depois da transferência dos órgãos públicos e, assim, buscamos destacar os processos globais, modernizadores e políticos que foram preenchendo o cotidiano daqueles moradores. De modo geral, Goiânia pode ser um exemplo que reflete as dinâmicas globais das décadas de 1930 e 1940, seja no tocante ao modo como sua construção foi pautada nas modernas formas de pensar a cidade, seja no que se refere ao modo como o jornal $O$ Popular objetivou inserir seus moradores em uma atmosfera modernizadora, ou, ainda, às estratégias elaboradas pelo poder público - local e federal - no ímpeto de inseri-la no cenário nacional.

\section{Referências}

ARANHA, O. Homenagem. O Popular, Goiânia, p. 4, 23 jun. 1942.

ARRAIS, T. A. A produção do território goiano - economia, urbanização, metropolização. Goiânia: Ed. da UFG, 2013.

CÂMARA JR., J. 50 anos de O Popular. O Popular, Goiânia, p. 4, 6 ago. 1988.

CAMPANHA pró-bandeirante. O Popular, Goiânia, p. 2, 28 jun. 1938.

CAMPINAS. O Popular, Goiânia, p. 30, 10 jul. 1938.

CAPELATO, M. H. R. Multidões em cena. Propaganda política no varguismo e no peronismo. Campinas: Papirus, 1998. 310p.

CARNAVAL de 1939. O Popular, Goiânia, p. 4, 26 fev. 1939.

CHAUL, N. F. A construção de Goiânia e a transferência da capital. Goiânia: UFG, 1999.

COELHO, G. L. S. O bandeirante que caminha no tempo: apropriações do poema "Martim Cererê" e o pensamento político de Cassiano Ricardo. 2015. 346 f. Tese (Doutorado em História) - Universidade Federal de Goiás, Goiânia, 2015.

DOAÇÕES para a campanha pró-bandeirante. O Popular, Goiânia, p. 1, 21 ago. 1938.

EDITORIAL. O Popular, Goiânia, p. 1, 9 jul. 1942.

FERRAZ, H. Cidade e vida. São Paulo: Scortecci, 1996. 
INAUGURAÇÃO oficial. O Popular, Goiânia, p. 1, 29 jan. 1942.

JÓQUEI Clube. O Popular, Goiânia, p. 2, 30 jul. 1942.

HOBSBAWN, E.; RANGER, T. A invenção da tradição. Rio de Janeiro: Paz e Terra, 1997. 149p.

LUCA, T. R. de. História dos, nos e por meio dos periódicos. In: PINSKY, C. B. (org.). Fontes históricas. $2^{\mathrm{a}}$ ed. São Paulo: Contexto, 2008. v. 1, p. 111-153.

MACHADO, M. Pedro Ludovico: um tempo, um carisma, uma história. Goiânia: UFG, 1990.

MARCONDES FILHO, C. O capital da notícia. São Paulo: Ática, 1989

NORA, P. Entre memória e história: a problemática dos lugares. Tradução: Yara Aun Khoury. Projeto história. Revista do Programa de Estudos Pós-graduados em História do Departamento de História da PUC-SP, São Paulo, p. 7-22, 1981.

NOTÍCIAS sobre a inauguração de Goiânia. O Popular, Goiânia, p. 4, 23 jul. 1942.

PALACIN, L. História de Goiás. 6ª ed. Goiânia: UCG, 1994.

PREPARATIVOS para a inauguração. O Popular, Goiânia, p. 2, 12 fev. 1942.

. O Popular, Goiânia, p. 3, 14 jun. 1942.

REMODELAÇÃO de Campinas. O Popular, Goiânia, p. 1, 12 maio 1938.

RICARDO, C. Marcha para Oeste: a influência da bandeira na formação social e política do Brasil. São Paulo: José Olympio, 1940. 580 p.

ROCHA, H. Sete décadas de Goiânia. Goiânia: Contato Comunicação, 2003.

ROCHA, D. M. M. Modernidade dos Interiores Art Déco de Goiânia. SEMINÁRIO NACIONAL DE PESQUISA EM ARTE E CULTURA VISUAL, 5., 2012. Goiânia. Anais [...]. Goiânia: UFG: FAV, 2012. Disponível em: https://files.cercomp.ufg.br/weby/up/778/o/2012-33_A_modernidade.pdf. Acesso em: 15 ago. 2021.

SANTOS, M. Metamorfoses do espaço habitado. São Paulo: Hucitec, 1988.

SILVA, L. S. D. da. Progresso e sertão goiano: a espera. In: BOTELHO, T. (org.). Goiânia: cidade pensada. Goiânia: Ed. da UFG, 2002.

SILVA, J. F. Quando o Anhanguera cruza Goiás: o Monumento aos Bandeirantes na nova capital. 2020. 198 f. (Dissertação de Mestrado) - Faculdade de Filosofia e Ciências Humanas, Universidade Federal de Minas Gerais, Belo Horizonte, 2020.

SILVA, J. F.; PINTO, A. M. A. A dimensão simbólica do espaço urbano: os monumentos e a memória social de uma cidade planejada. In: ASOCIACIÓN DE ESCUELAS Y FACULTADES PÚBLICAS DE ARQUITECTURA DE AMÉRICA DEL SUR, 2019, Belo Horizonte. Anais eletrônicos [...]. Campinas, Galoá, 2019. Disponível em: https://proceedings.science/arquisur-2019/papers/a-dimensao-simbolica-do-espaco-urbano--os-monumentos-e-a-memoria-social-de-uma-cidade-planejada?lang=pt-br. Acesso em: 15 ago. 2021.

SOARES, F. de M. Telegrama. O Popular, Goiânia, p. 3, 22 jan. 1942.

SODRÉ, N. W. História da imprensa no Brasil. Rio de Janeiro: Civilização Brasileira, 1966.

SORVETERIA Vera Cruz. O Popular, Goiânia, p. 3, 1º maio 1938. 
SOUZA, C. V. Batismo cultural de Goiânia: um ritual da nacionalidade em tempos de Marcha para Oeste. In: BOTELHO, T. R. et al. Goiânia: cidade pensada. Goiânia: Ed. da UFG, 2002. p. 71-102.

VARGAS, G. Cruzada Rumo ao Oeste. In: GUASTINI, R. O ideário político de Getúlio Vargas. Rio de Janeiro: Revista dos Tribunais, 1943. p. 149-151

VICTOR, M. Pronunciamento na Rádio Bandeirante. O Popular, Goiânia, p. 2, 19 maio 1938. 


\section{George Leonardo Seabra Coelho}

Bacharel e licenciado em História pela Universidade Federal de Goiás (UFG). Mestre e doutor em História pela mesma instituição. Pós-doutor em História pela Universidade Federal do Estado do Rio de Janeiro (Unirio) e pela UFG. Professor adjunto da Universidade Federal do Tocantins (UFT), pertencente ao quadro permanente do Programa de Pósgraduação em História das Populações Amazônicas (PPGHispam). É líder do Grupo de Pesquisa CNPq em Mídias, Tecnologias e História (Mitechis). Atualmente realiza estágio de pós-doutoramento no Programa de Pós-graduação em Educação (PPGE) na UFT.

Email: george.coelho@hotmail.com

ORCID: 0000-0002-3166-4008

Submissão: 11 de fevereiro de 2021.

Aprovação: 14 de outubro de 2021.

Como citar: COELHO, G. L. S. Cotidiano, imprensa e política: a construção simbólica da cidade de Goiânia por intermédio do jornal O Popular. Revista brasileira de estudos urbanos e regionais. V. 23, E202143, 2021. DOI 10.22296/2317-1529.rbeur.202143

Artigo licenciado sob Licença Creative Commons CC BY 4.0.

https://creativecommons.org/licenses/by/4.o/deed.pt_BR 